\title{
Impact of advanced electricity tariff structures on the optimal design, operation and profitability of a grid-connected PV system with energy storage
}

\author{
Lionel Bloch ${ }^{*}$, Jordan Holweger ${ }^{\dagger}$, Christophe Ballif and Nicolas Wyrsch \\ From The 8th DACH+ Conference on Energy Informatics, \\ Salzburg, Austria. 26-27 September, 2019
}

\author{
*Correspondence: \\ lionel.bloch@epfl.ch \\ ${ }^{\dagger}$ Lionel Bloch and Jordan Holweger \\ contributed equally to this work. \\ École Polytechnique Fédérale de \\ Lausanne (EPFL), Institute of \\ Microengineering (IMT), \\ Photovoltaics and thin film \\ electronics laboratory (PV-LAB), Rue \\ de la Maladière 71b, 2002 \\ Neuchâtel, Switzerland
}

\begin{abstract}
The increasing penetration of residential photovoltaics (PV) comes with numerous challenges for distribution system operators. Technical difficulties arise when an excess of PV energy is injected into the grid, causing voltage rise or overloading of the lines. Economic challenges appear because PV owners and consumers are not participating equally in the grid costs. Indeed, PV owners benefit by self-consuming their PV production and by gaining additional revenues when they sell their PV surplus to the grid. Hence, they lower their grid costs. In this paper, we propose a mixed-integer-linear programming approach to solve the design and operation of a PV and battery system efficiently. We use this tool to benchmark five different tariff scenarios, which include real-time pricing, a capacity-based tariff, and a block rate tariff, and evaluate their effect on the design and operation of the system. Carefully tailored metrics show the impact of these tariff structures on the trade-off between the economic viability of privately owned energy systems and their grid usage intensity. Considering both aspects, we show that a block rate tariff is the most promising approach and that capacity-based tariffs rely on PV curtailment alone to curtail the generation peaks.
\end{abstract}

Keywords: MILP, Photovoltaic, Battery, Tariff design

\section{Introduction}

The increasing penetration of distributed renewable energy in local distribution networks introduces numerous exploitation challenges for distribution system operators. In particular, the high penetration of photovoltaics (PV) in a residential district may cause over-voltages or breaking of the line thermal limit, which can be overcome with grid reinforcement at a high cost (Theo et al. 2017). The increasing usage of the grid, proportional to the maximum power exchanged with the grid, is hence one of the barriers to a high penetration of residential PV. Additionally, since the current business model of PV owners is to reduce their electricity bill thanks to self-consumption (Kubli 2018), social equity issues arise. Indeed the current tariff structures do not allow the network operator to recover grid costs from PV owners. At least, any attempt may reduce the attractiveness

(c) The Author(s). 2019 Open Access This article is distributed under the terms of the Creative Commons Attribution 4.0 International License (http://creativecommons.org/licenses/by/4.0/), which permits unrestricted use, distribution, and reproduction in any medium, provided you give appropriate credit to the original author(s) and the source, provide a link to the Creative Commons license, and indicate if changes were made. 
of PV investment (Huber et al. 2018). To address these issues, carefully tailored demandside management measures must be implemented to promote investment in flexible PV energy systems while not penalizing PV technologies. As a tool, energy retail tariff and grid fees could enable this flexibility. Regarding energy retail tariff, we can distinguish four different pricing strategies (Dutta and Mitra 2017):

Flat rate A common electricity tariff strategy, flat rate consists of a price proportional to the energy exchanged (i.e. in $\mathrm{CHF} / \mathrm{kWh}$ ). By definition, this tariff is constant through time.

Time-of-use Also common for larger residential consumers. A lower energy rate $(\mathrm{CHF} / \mathrm{kWh})$ typically applies during the night. In general, time-of-use tariffs have a variable rate according to the time of the day.

Critical peak pricing Similar to the time-of-use tariff, critical peak pricing sets a higher energy price $(\mathrm{CHF} / \mathrm{kWh})$ during periods of high demand, typically cooking time, on an everyday basis. An extension of this pricing policy is variable peak pricing which may consider daily variations of both the peak hours and the tariffs.

Real-time pricing The energy tariff is indexed with the spot energy market prices for instance. Hence the energy tariff can vary on a 15- or 60-min basis.

Although network charges for the residential sector are mixed with the retail energy price in the form of a volumetric charge $(\mathrm{CHF} / \mathrm{kWh})$, alternative grid fees also exist (Azarova et al. 2018):

Fixed charges A fixed annual fee, which may depend on the power capacity of the connection point, that is independent of both the energy consumption and the used power capacity.

Capacity based grid costs are paid on a monthly (or yearly) basis and based on the maximum measured power $(\mathrm{CHF} / \mathrm{kW})$. Usually, the capacity tariff is time-independent, but it can vary on a seasonal basis.

Block rate tariff An energy tariff $(\mathrm{CHF} / \mathrm{kWh})$ that varies according to the (averaged) power over a 15-min period. The energy tariff usually increases with the power interval, thus forming blocks. More details are given in "Objective function" section.

To realize the flexibility, emerging technologies such as battery energy storage are needed. The latter is particularly promising to increase the flexibility of PV systems, but the economic viability of this technology is still under debate and depends strongly on the underlying electricity tariff design (Milis et al. 2018).

This paper aims to study the impact of the most-up-to-date tariff structures provided by the literature on the optimal operation and design of a grid-connected residential PV-battery system. First, an integrated optimization of both the component sizing and control, based on mixed integer linear programming (MILP) is proposed. Then, appropriate performance metrics are defined allowing us to assess how tariff structures mitigate grid usage and prevent excessive power injection or withdrawal while preserving financial sustainability for the investor. This paper is organized as follows: "Related work" section presents the most relevant literature, "Methodology" section introduces the formulation of the optimization problem and the relevant performance metrics, "Case study" 
section briefly introduces the considered case study, and "Results and discussion" section discusses and analyzes the optimizations. Finally, "Conclusions" section draws conclusions and provides insight for policy makers and future research directions.

\section{Related work}

In the early adoption of residential photovoltaics, the design of feed-in tariffs was disputed in order to avoid overcompensation for the government. A high feed-in tariff incentivizes investment in distributed generation and transfers market price risk from investors to consumers (Devine et al. 2017). Ayompe et al. (2013) analyzed various feed-in tariffs and proposed multiple (even continuous) tariffs at which household investment becomes profitable. They showed how current feed-in tariffs generate overcompensation and how tuning them over a group of households limits this effect. The increasing maturity of PV technologies correlates with increasing PV penetration, thus sparking the need to re-think grid tariffs. Huber et al. (2018) acknowledged this issue by claiming that the current way grid costs are charged promotes desocialization of grid costs. As predominantly wealthy households can invest in PV installations and equip their house with storage, their electricity consumption from the grid decreases until they become net energy producers. In this way, their participation in covering the grid costs is decreasing while lower-income households will have to cover a bigger share of the grid costs. In Bonbright's reference book (Bonbright et al. 1961), some basic guidelines of utility rate structure are stated. The most relevant of these requirements for energy distribution is that grid fees should be understandable and publicly acceptable, guarantee the minimum revenue to recover the investment cost in a "fair-return standard", discourage any wasteful use of the infrastructure and ensure "fairness (...) in the apportionment of total costs of service among the different consumers".

Most of the adopted volumetric grid charge schemes (cost and revenue are proportional to the exchanged energy, as defined in (Hinz et al. 2018)) do not completely satisfy this last rule. Simshauser (2016) showed that in terms of peak demand, PV owners have a grid usage similar to standard consumers. He proposed to integrate a demand tariff (proportional to the maximum peak demand of a year), showing how such a tariff avoids an indirect subsidy to PV owners. Schittekatte et al. (2018) have shown that high enough capacity-based charges, whose cost is proportional to the peak exchanged power, as defined in (Hinz et al. 2018), can over-incentivize investment in PV and batteries and might lead to inequity between passive consumers and prosumers. The risk described in the latter paper is that individual investment decisions might lead to over-investment in distributed renewable energy sources, which might cause an increase in the total system costs. In a world pushing toward decarbonization, incentivizing distributed renewable energy sources is a key lever. Kubli (2018) argues that promoting the diffusion of distributed PV clearly comes with the promotion of self-consumption, hence a reduction of the volumetric exchange with the grid. The capacity-based tariff allows for appropriate re-allocation of the grid costs while promoting self-consumption but still causes a re-distribution of the grid costs among consumers and prosumers.

One has, however, to distinguish between grid fees and energy supply costs. The first aims at covering the cost of the distribution infrastructure while the second should be representative of the availability of a particular amount of energy at a specific time given the overall demand. In most of the following reviewed papers, network charges are often 
considered together with energy supply charges. While the most-adopted energy pricing mechanism is a simple flat rate (which includes grid fees in a volumetric way), the review of (Dutta and Mitra 2017) proposes an overview of dynamic pricing mechanisms. According to the authors, the primary motivation for introducing dynamic pricing of electricity is to avoid an unnecessary peak load that has to be covered by expensive production reserve capacity. In this way, time-of-use (TOU) and real-time pricing are useful pricing mechanisms to encourage consumer demand to respond to a given price signal. The design of such a dynamic tariff is however not straightforward. This challenge is addressed by Soares et al. (2019) who proposed a bi-level optimization approach to design TOU pricing while maximizing the retailer profit and modeling the reaction of a set of consumers to those prices.

Many authors also studied the impact of various network tariff schemes on the different stakeholders' revenues (or expenses). Starting with the grid operator, Young et al. (2016) explored the impact of various PV penetration levels and energy efficiency measures (modeled as energy savings) on the contribution of individual households to the network cost. The extension of this work conducted by the same authors (Young et al. 2019) aims at modeling the impact of the use of residential batteries on the network revenue under various considered storage and PV capacity and under various tariff structures. The authors show that aiming to maximize self-consumption with a $\mathrm{PV}$ and battery system is beneficial for the network in the sense that it reduces the peak demand, thus the network cost.

Regarding the impact of grid tariffs on household energy bills, Azarova et al. (2018) analyzed the effect of 11 hypothetical network tariffs on the energy bills of 765 households. Thanks to an appropriate investigation of the households' socio-economic data, the authors observed which socio-economic groups might benefit or suffer from different tariff structures. The authors highlighted the rising risk of inequity between consumers and prosumers with a relatively higher income. Focusing more specifically on the potential benefits to residential PV owners, Dargouth et al. (2016) investigated how the evolution of the wholesale market design impacts the market price of electricity and, in turn, the bill savings of PV owners. Their work shows the trade-off between having an efficient market design and supporting the deployment of distributed PV. Ren et al.(2016) analyzed the financial benefit of a PV and battery system under nine different tariff scenarios combining three network components (fixed charges, capacity-based, and peak demand) and three retail energy components (flat, time-of-use, and critical peak price). The highest bill savings are achieved with capacity-based and critical peak price energy rates. Borenstein (2017) analyzed the effect of rebates and tax incentives on the net present value of US residential PV installations, showing that wealthier households get higher profitability from their PV installations than lower-income households, due to their larger system sizes, higher consumption and lower interest rates. As emerging business models arise, such as flexibility providers and aggregators of distributed energy storage system to provide grid services, Govaerts et al. (2018) studied the strategic operation of an aggregator of residential PV and energy storage systems under various distribution tariffs. The best profitability of a flexibility aggregator against an energy retailer is achieved under a capacity-based tariff. In the papers mentioned earlier, the authors used pre-defined scenarios of the system design. In other words, the authors performed a parametric analysis such as in (Schibuola et al. 2016), but no optimization to find the 
most appropriate design of the considered energy systems according to any financial metrics.

The optimization of energy systems is performed along two axes. The first axis is the operation of the system and the second axis is its design, namely the components' sizes. In (Babacan et al. 2017), a convex optimization problem is formulated to provide the optimal scheduling of a battery co-located with an existing residential PV system. The authors proposed a formulation to integrate the monthly capacity charges in the objective function. Pena-Bello et al. (2017) used a genetic algorithm to optimize the daily operation of a battery to minimize the daily electricity bill. This approach takes advantage of the non-linear solver to analyze different battery usage strategies. The authors showed that in Switzerland, at the current battery price level, such a system is never profitable for any of these applications. Zhang et al. (2019) recently also used a genetic algorithm to solve the optimal scheduling of a battery and PV system under both a TOU tariff and a block rate tariff. Although the authors did not discuss the potential benefit of the reaction of the energy manager to a block rate tariff, they showed that economic gain is possible in China.

In (Mulder et al. 2013), implemented a simple rule-based algorithm to solve the operation of a battery combined with PV and optimized the size of the PV and battery capacity using a combinatorial approach (namely evaluating the net present value for a given set of combination). The focus of this study is related to the influence of the (flat) import and export tariff on the optimal size of a PV and battery system. A convex programming approach is used in (Wu et al. 2017) to find the optimal size and daily operation of a battery for a given installed PV capacity under a given feed-in power limit.

The integrated optimization of the PV and battery sizing and energy management can be solved following two kinds of formulations: either non-linear programming techniques or convex (linear or quadratic) programming. A non-linear approach is used in (Ansari et al. 2016) in order to include the formulation of the voltage support to the grid. Using a similar method, (O'Shaughnessy et al. 2018) includes (among others) a non-linear model of the air conditioning. A linear model is used in (Lauinger et al. 2016) to provide a general decision-making tool for large energy systems. In (Deetjen et al. 2018), the authors included a linear model of a chiller, thermal energy storage, and micro-turbine generator to study the optimal component sizing with different time-of-use electricity rate structures. Similarly, a two-stage formulation is proposed by Talent et al. (2018) to solve first the optimal design according to the estimated net present value of the system, and second the energy management to minimize the electricity bills under a time-of-use rate and capacity-based tariff.

The papers mentioned above provide a broad overview of the current state-of-theart on operational research. As was discussed, providing an appropriate price signal to encourage flexibility also comes with equity issues concerning standard consumers because the business model of a prosumer is to avoid buying energy from the grid while its grid usage remains unchanged or even increases. Alternative tariff structures come with significant financial impacts for both households and distribution system operators. The impact of electricity rate structures on the financial incentives to install PV and electricity storage systems is not deeply discussed by the community, especially the specific angle of the relationship between grid usage and electricity rate structures. 
Our approach differs from (Babacan et al. 2017; Zhang and Tang 2019; Mulder et al. 2013; Wu et al. 2017) by considering the optimization of both the sizing of the PV and battery system and its operation using a fully integrated formulation contrary to a two-step optimization as in (Talent and Du 2018). Compared to the latter, our approach ensures that we have a global optimum of the net present value but take into account neither PV degradation nor the consumption evolution. Additionally, we consider a convex formulation which ensures optimality of the solution instead of meta-heuristic solver as in (Ansari et al. 2016; O'Shaughnessy et al. 2018). In comparison to (Deetjen et al. 2018), we choose a finer temporal resolution $(15 \mathrm{~min}$ ), which is closer to the recommendation of (Bucher et al. 2013; Beck et al. 2016) for modeling variable renewable energy sources. Additionally, we integrate more-advanced tariff structures such as the block rate tariff and capacity tariff inspired by Schreiber et al. (2015) into the design optimization problem while adding a real-time pricing energy tariff.

In addition to the standard performance metric to assess the usage of the grid such as maximum peak power, self-consumption and self-sufficiency (Simshauser 2016; Schittekatte et al. 2018; Kubli 2018), we consider another grid usage metric which compares the maximum power exported or imported with the maximum load power. Finally, we discuss the relevance of the tariff structure concerning the contradictory goal of promoting distributed PV systems and providing a fair electricity rate that respects the principle of proportionality of grid usage.

\section{Methodology}

\section{System description}

The considered energy system (depicted in Fig. 1) is a single building with multiple roof planes, each section of roof being potentially covered by PV modules whose generation can be curtailed if needed. The building is equipped with one or more battery storage systems and is connected to the main AC grid.

\section{System modeling}

This section presents the optimization model for the design and operation of a gridconnected PV and battery system formulated as a MILP problem. In order to take into account seasonal effects and ensure plausible operation, the optimization is carried out over a full year similarly to (Talent and $\mathrm{Du} 2018$ ). To optimize the design of the PV installation, a set of configurations is defined for each roof. For instance, a flat roof could have two configurations, a south-oriented and an east-west configuration. Each configuration has its pre-calculated generation profile $P^{\mathrm{MOD}}[\mathrm{W}]$ for a full year, i.e. the production of the smaller possible unit (one module in general or two modules for the east-west configuration). Moreover, we assume that the investment cost for each configuration is linear, with a fixed part $\mathrm{CF}^{\mathrm{PV}}[\mathrm{CHF}]$ and a variable part $C^{\mathrm{MOD}}[\mathrm{CHF} / \mathrm{W}]$. In order to avoid shadowing, each configuration has a footprint $A^{\mathrm{MOD}}$ that depends on its orientation. Note that the fixed cost $\mathrm{CF}^{\mathrm{PV}}$ is paid only once even with many roofs and configurations. The optimization then returns the optimal number of units per configuration in order to minimize the objective function, considering the space constraint (detailed below).

This sizing of $B$ number of batteries is also optimized. Each battery has an initial state of charge $\mathrm{SOC}_{0}$ and range ( $\mathrm{SOC}_{\min \text {,max }}$ ), a self-discharge rate $\alpha$, charging and discharging 


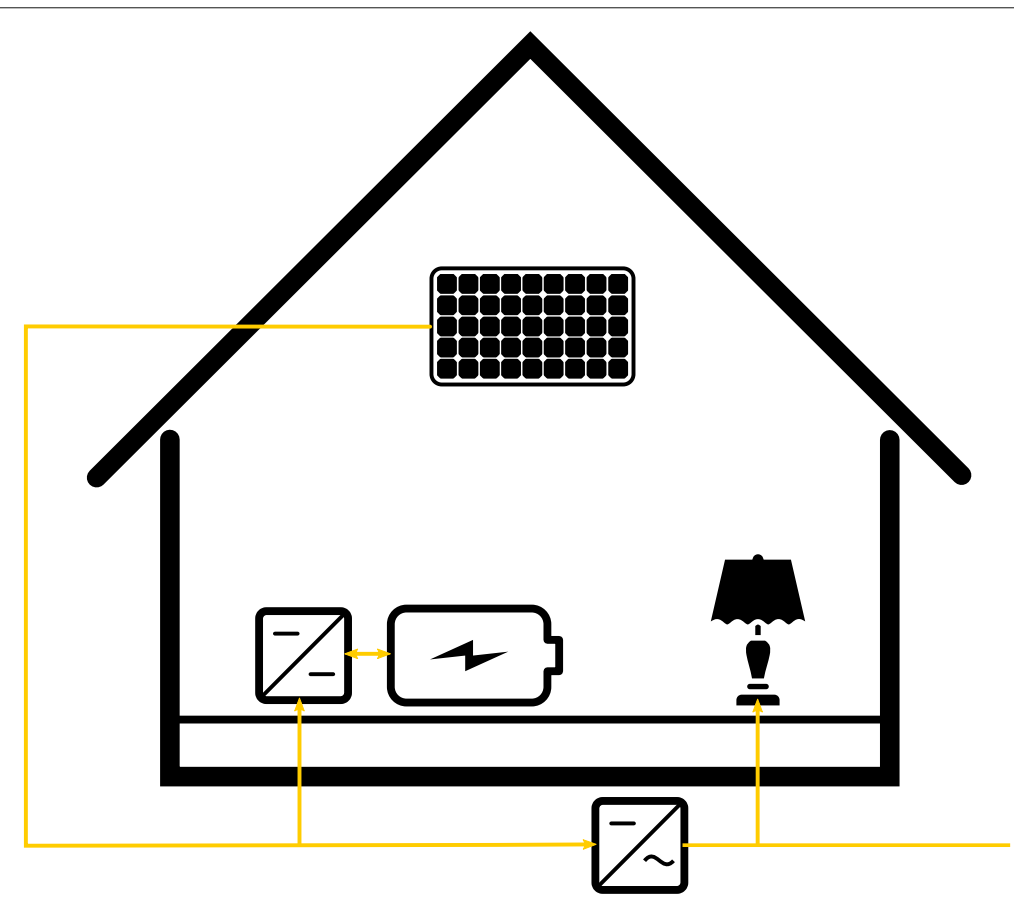

Fig. 1 System under study

efficiency $\left(\eta^{\mathrm{CHA}, \mathrm{DIS}}\right)$, charging and discharging $\mathrm{C}$-rate $\left(\gamma^{\mathrm{CHA}, \mathrm{DIS}}\right)$ and finally a specific cost $C^{\mathrm{BAT}}$ and fixed $\operatorname{cost} C_{F}^{\mathrm{BAT}}$ as well as an operational cost of storage $C_{O}^{\mathrm{BAT}}$.

All the parameters and their values of this model are reported in Table 5 from "Case study" section with their respective units. Table 1 defines the decision variables used in this paper.

The model is composed of a set of constraint equations that ensure energy conservation and model each part of the system, namely the PV system and the battery system.

\section{Energy conservation}

The first constraint of the system is energy conservation at any time. The power imported from the grid, battery(ies) discharge, and PV generation must be balanced by the power

Table 1 Decision variables

\begin{tabular}{lllll}
\hline & Variable & Set & Unit & Description \\
\hline GRID & $p^{\text {IMP }}$ & $\mathbb{R}_{+}^{T}$ & W & imported power (from the grid) \\
& $p^{\text {EXP }}$ & $\mathbb{R}_{+}^{T}$ & W & exported power (to the grid) \\
& $p^{\text {CUR }}$ & $\mathbb{R}_{+}^{T}$ & W & curtailed power \\
PV & $P^{\text {MAX }}$ & $\mathbb{R}_{+}^{M}$ & monthly exchange peak \\
& $n^{\text {MOD }}$ & $\mathbb{N}^{N}$ & - & PV configurations, number of units \\
& $b^{\text {MOD }}$ & $\{0,1\}^{N}$ & - & PV configurations active $(\mathrm{Y} / \mathrm{N})$ \\
BATTERY & $b^{\text {PV }}$ & $\{0,1\}$ & - & PV installation, presence \\
& $P^{\text {CHA }}$ & $\mathbb{R}_{+}^{T \times B}$ & W & battery charging power \\
& $P^{\text {DIS }}$ & $\mathbb{R}_{+}^{T \times B}$ & W & battery discharging power \\
& $E^{\text {BAT }}$ & $\mathbb{R}_{+}^{(T+1) \times B}$ & $J$ & battery capacity \\
& $E^{\text {CAP }}$ & $\mathbb{R}_{+}^{B}$ & $J$ & nominal battery capacity \\
& $b^{\text {BAT }}$ & $\{0,1\}$ & - & battery, presence \\
\hline
\end{tabular}


exported to the grid, battery(ies) charging, PV curtailment and the load. This relation is formulated in Eq. 1 where the left part contains decision variables and the right part the load which is a problem parameter.

$$
P_{t}^{\mathrm{IMP}}-P_{t}^{\mathrm{EXP}}-\sum_{B} P_{t, b}^{\mathrm{CHA}}+\sum_{B} P_{t, b}^{\mathrm{DIS}}-P_{t}^{\mathrm{CUR}}+P_{t}^{\mathrm{PV}}=P_{t}^{\mathrm{LOAD}} \quad \forall t \in T
$$

where $P_{t}^{\mathrm{IMP}, \mathrm{EXP}}$ is the imported/exported power from the grid respectively, $P_{t, b}^{\mathrm{DIS}, \mathrm{CHA}}$ is the discharge/charge power of each battery, $P_{t}^{\mathrm{PV}}$ is the total PV generation (W) which depends on the PV configuration variables, $P_{t}^{\text {CUR }}$ is the power curtailed from the PV generation and $P_{t}^{\mathrm{LOAD}}$ is the load.

\section{PV system model}

The total PV generation is defined as the sum of the power generation of each configuration and the chosen number of modules per configuration as indicated in Eq. 2. $P_{t, i}^{\mathrm{MOD}}$ is the power generated by one unit of the $i^{\text {th }} \mathrm{PV}$ configuration oriented with an azimuth $\theta_{i}$ and tilt $\beta_{i}$. $P^{\mathrm{MOD}}$ is then a matrix of size $[T \times N]$ representing the pre-calculation of the PV output as a function of the selected configurations. Each configuration has a footprint $A_{i}^{\mathrm{MOD}}$. Thus the decision variable $n_{i}^{\mathrm{MOD}}$ is an integer value constrained by the area of the corresponding roof $A_{j}^{\mathrm{ROOF}}$. This constraint is modeled in Eq. 3.

$$
\begin{aligned}
P_{t}^{\mathrm{pV}} & =\sum_{i=1}^{N} P_{t, i}^{\mathrm{MOD}} \cdot n_{i}^{\mathrm{MOD}} \\
\sum_{i=1}^{N_{j}} n_{i}^{\mathrm{MOD}} \cdot A_{i}^{\mathrm{MOD}} & <A_{j}^{\mathrm{ROOF}} \quad \forall j \in J \\
\frac{D}{H} & =\frac{\sin (\alpha+\beta)}{\sin (\beta)} \\
P_{t}^{\mathrm{CUR}}-P_{t}^{\mathrm{PV}} & <0
\end{aligned}
$$

The area $A_{i}^{\mathrm{MOD}}$ is simply the module area if the module is set on a tilted roof. $N_{j}$ is the ensemble of configuration for the $j^{\text {th }}$ roof such that $\sum_{j=1}^{J} N_{j}=N$. In the case of a flat roof, where modules are mounted on racks, a simple geometric model is used to compute the footprint as pictured in Fig. 2. In the case of an east-west configuration, $A_{i}^{\mathrm{MOD}}$ is the projected surface of two modules with a chosen tilt angle. For a single-orientation configuration, $A_{i}^{\mathrm{MOD}}$ is $\frac{D}{H}$ times the area of the modules (this ratio is calculated in Eq. 4), where $H$ is the module width and $D$ the distance between two modules given by Eq. 4 . The angle $\beta$ is the minimum solar elevation to avoid shadowing, which is by default $20 \mathrm{deg}$, corresponding to the elevation of the sun at noon during winter in Switzerland. Finally, the curtailment of the PV surplus is a decision variable that cannot exceed the total PV generation as formulated in Eq. 5.

\section{Battery model}

The battery model is derived from (Heussen et al. 2010) and (Stadler et al. 2016). Although the model could be valid for any electricity storage system technology, we consider here a lithium manganese oxide (LMO) battery. The model applies for each battery considered in the system. In order to simplify the notation, the subscripts $b$ have been removed. The model ensures the continuity of the energy stored in the battery by Eq. 6, considering 


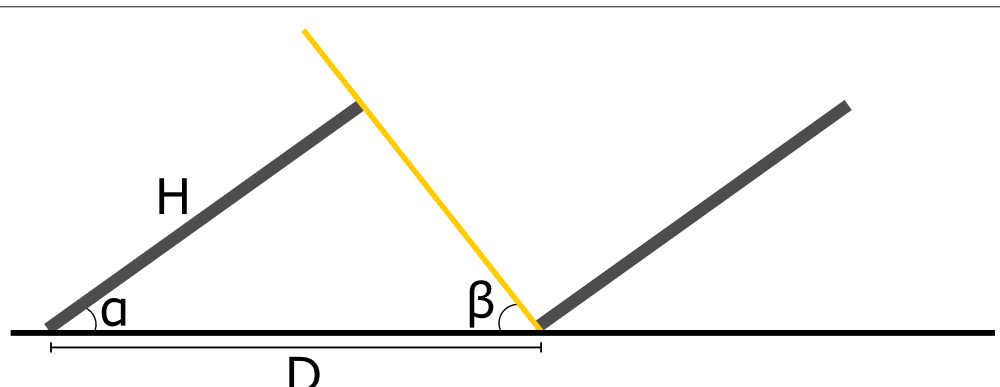

Fig. 2 Distance $D$ between two modules for a given module height $H$, tilt angle $\alpha$ and solar elevation $\beta$

the self-discharge coefficient $\alpha$, and the charge/discharge efficiency $\eta^{\mathrm{CHA}, \mathrm{DIS}}$. In order to replicate the cyclicity of the operation, the initial amount and final amount of energy stored in the battery are fixed by Eqs. 7 and 8 with $\mathrm{SOC}_{0}$ the initial state of charge. The battery should operate within the given bounds of the state of charge $\mathrm{SOC}_{\min }$ and $\mathrm{SOC}_{\max }$, according to Eq. 9. The charge and discharge powers are also constrained according to the $\mathrm{C}$-rate parameters $\gamma^{\mathrm{CHA}}$ and $\gamma^{\text {DIS }}$ (given in 1/s). This constraint is expressed in Eq. 10.

$$
\begin{aligned}
& E_{t+1}^{\mathrm{BAT}}-\alpha E_{t}^{\mathrm{BAT}}-\eta^{\mathrm{CHA}} P_{t+1}^{\mathrm{CHA}} \cdot \mathrm{TS}_{t}+\frac{1}{\eta^{\mathrm{DIS}}} P_{t+1}^{\mathrm{DIS}} \cdot \mathrm{TS}_{t}=0 \\
& E_{0}^{\mathrm{BAT}}-\mathrm{SOC}_{0} \cdot E_{\mathrm{CAP}}^{\mathrm{BAT}}=0 \\
& E_{T}^{\mathrm{BAT}}-E_{0}^{\mathrm{BAT}}=0 \\
& -E_{t}^{\mathrm{BAT}}+\mathrm{SOC}_{\min } \cdot E_{\mathrm{CAP}}^{\mathrm{BAT}}<0 \\
& E_{t}^{\mathrm{BAT}}-\mathrm{SOC}_{\max } \cdot E_{\mathrm{CAP}}^{\mathrm{BAT}}<0 \\
& P_{t}^{\mathrm{CHA}}-E_{\mathrm{CAP}}^{\mathrm{BAT}} \cdot \gamma^{\mathrm{CHA}}<0 \\
& P_{t}^{\mathrm{DIS}}-E_{\mathrm{CAP}}^{\mathrm{BAT}} \cdot \gamma^{\mathrm{DIS}}<0
\end{aligned}
$$

\section{Objective function}

The objective function summarizes the ultimate goal of the optimization problem, namely minimizing the total expense over a given period. In this case, the total annualized cost (Eq. 11) is the sum of the annual operating cost (OPEX) and the annualized investment cost (CAPEX). The latter is defined in Eq. 13 with $R$ being the capital recovery factor (defined in Eq. 14) as a function of the annual discount rate, $r$, and the system lifetime, $L$. The ratio $L / L^{\mathrm{BAT}}$ is an approximation that represents the expected number of replacements of the battery over the entire system lifetime in the investment costs.

$$
\begin{aligned}
\text { TOTEX } & =\text { OPEX }+R \cdot \text { CAPEX } \\
\text { OPEX } & =\text { OX }_{\mathrm{ge}}+\mathrm{OX}_{\mathrm{bo}}+\mathrm{OX}_{\mathrm{pm}} \\
\text { CAPEX } & =\mathrm{CX}_{\mathrm{pv}}+\frac{L}{L^{\mathrm{BAT}}} \cdot \mathrm{CX}_{\mathrm{bat}} \\
R & =\frac{r \cdot(1+r)^{L}}{(1+r)^{L}-1}
\end{aligned}
$$


The operating cost is composed of three parts (Eq. 12): First, the costs associated with the exchange of energy with the grid. Second, the battery operation expenses which consists of a cost, $C_{O}^{\mathrm{BAT}}$, proportional to the battery's discharged energy. This parameter allows for reducing the intensity of usage of the battery. It can be considered as a tuning parameter of the model. Finally, PV maintenance costs are proportional to the PV capital investment by a factor $\gamma^{\mathrm{PV}}$. The definition of each part is reported in Table 2.

The grid exchange costs depend on the tariff structure. In the following, three kinds of tariff structure are defined: a volumetric tariff, a capacity tariff (the cost is proportional to the maximum power, evaluated monthly on both import and export) and a block rate tariff where the volumetric tariff depends on the power level at which the energy is exchanged. Volumetric tariffs are simply the product of the energy imported (or exported) and the corresponding import and export tariff $\left(t_{t}^{\mathrm{IMP}, \mathrm{EXP}}\right.$ as depicted in Eq. 15a. Note that a tariff can be constant in time or periodic over a day (or even a week) or even fully timedependent. A capacity-based tariff is defined in Eq. $15 \mathrm{~b}$ where the maximum power $P_{m}^{\mathrm{MAX}}$ is defined based on constraints given in Eq. 16, in which $\delta_{m, t}$ is a Boolean variable that takes the value one if the time $t$ falls in month $m, 0$ otherwise.

$$
\begin{aligned}
& \text { Volumetric tariff } \\
& \mathrm{OX}_{\mathrm{ge}}^{\mathrm{vol}}=\sum_{t=1}^{T}\left[P_{t}^{\mathrm{IMP}} \cdot t_{t}^{\mathrm{IMP}}-P_{t}^{\mathrm{EXP}} \cdot t_{t}^{\mathrm{EXP}}\right] \cdot \mathrm{TS}_{t} \\
& \mathrm{Ox}_{\mathrm{ge}}^{\mathrm{pow}}=\sum_{m=1}^{M} P_{m}^{\mathrm{MAX}} \cdot t^{\mathrm{MAX}} \\
& \mathrm{Ox}_{\mathrm{ge}}^{\text {block }}=\sum_{t=1}^{T} \max _{k=1 \ldots m}\left(P_{t}^{\mathrm{IMP}} \cdot a_{k}^{\mathrm{IMP}} \cdot \mathrm{TS}_{t}+b_{k}^{\mathrm{IMP}}\right) \\
& -\sum_{t=1}^{T} \min _{k=1 \ldots m}\left(P_{t}^{\mathrm{EXP}} \cdot a_{k}^{\mathrm{EXP}} \cdot \mathrm{TS}_{t}+b_{k}^{\mathrm{EXP}}\right) \\
& P_{t}^{\mathrm{IMP}}-\delta_{m, t} P_{m}^{\mathrm{MAX}}<0 \\
& P_{t}^{\mathrm{EXP}}-\delta_{m, t} P_{m}^{\mathrm{MAX}}<0
\end{aligned}
$$

The block rate tariff is built by setting a tariff $a_{k}$ between a power range $\left[p_{k-1}, p_{k}\right]$. It is created from a set of linear functions of slopes $a_{k}$ and intercepts $b_{k}$. The parameters $b_{k}$ can be found by the continuity of ox $\mathrm{ge}_{\mathrm{ge}}^{\mathrm{block}}$ in $p_{k}$ :

$$
\begin{aligned}
& b_{1}=0 \\
& b_{k}=\left(a_{k-1}-a_{k}\right) \cdot \mathrm{TS} \cdot p_{k-1}+b_{k-1} \quad \forall k>1
\end{aligned}
$$

An illustration of a three-block tariff is provided in Fig. 3.

Table 2 OPEX parts

\begin{tabular}{lll}
\hline Name & Notation & Definition \\
\hline grid exchanges & OXge & the costs associated with the grid exchange (eqs. 15a, 15b,15c) \\
battery operation & OX & $=\sum_{t=1}^{T} P_{t}^{D I S} \cdot C_{O}^{B A T} \cdot T S_{t}$ \\
pv maintenance & $O X_{p m}$ & $=\gamma^{P V} \cdot C X_{p v}$ \\
\hline
\end{tabular}




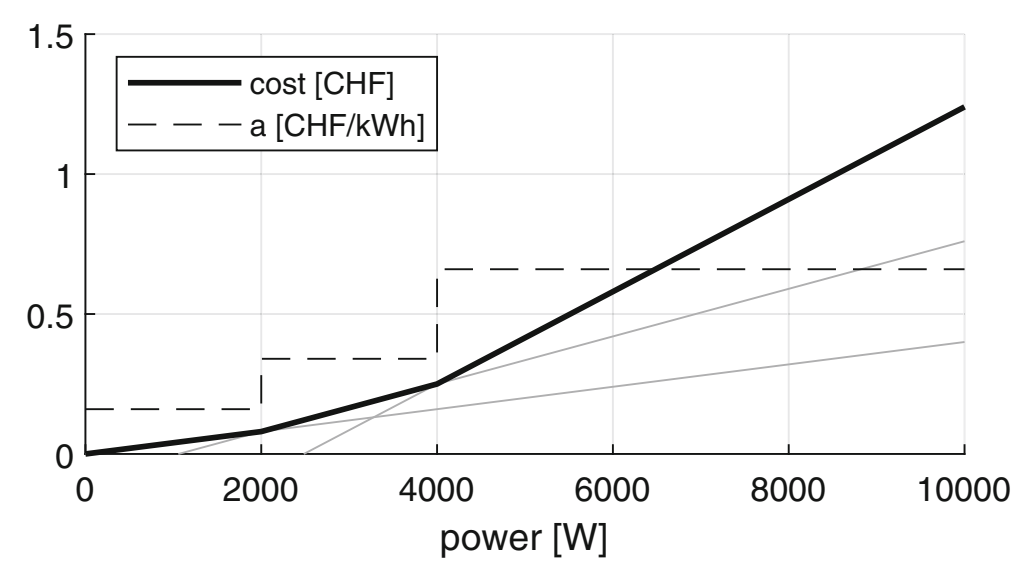

Fig. 3 Block rate tariff obtained by fixing the following tariff : $\mathrm{a}=(0.16,0.34,0.66) \mathrm{CHF} / \mathrm{kWh}$ for the power ranges $([0-2],[2-4],[4-\infty]) \mathrm{kW}$ with a time step of $15 \mathrm{~min}$

Finally, the CAPEX is composed of the PV and battery investment costs. The definitions of these costs are given in Table 3, where the unit cost of a configuration is proportional to the nominal power of a module, $P_{\text {nom }, i}^{\mathrm{MOD}}$, and the price per watt, $C_{i}^{\mathrm{MOD}}$. A fixed cost of installing $\mathrm{PV}, \mathrm{CF}^{\mathrm{PV}}$, is also considered if the Boolean variable $b^{\mathrm{PV}}$ is equal to 1 . Similarly, the cost of a battery is proportional to its capacity, $E_{\mathrm{CAP}, b}^{\mathrm{BAT}}$ and the specific cost (per J), $C^{\mathrm{BAT}, b}$, while the fixed cost, $C_{F}^{\mathrm{BAT}}$, is considered only if at least one battery is purchased ( $b^{\mathrm{BAT}}$ equal to 1$)$. The Boolean variables $b^{\mathrm{PV}}$ and $b^{\mathrm{BAT}}$ need to switch from 0 to 1 when the number of purchased modules $\sum_{i=1}^{N} n_{i}^{\mathrm{MOD}}$ or the total battery capacity $\sum_{b=1}^{B} E_{\mathrm{CAP}, \mathrm{B}}^{\mathrm{BAT}}$ is greater than zero. This is ensured in linear integer programming by adding the constraints formulated in Eq. 18, in which $G$ is a sufficiently large number.

$$
\begin{aligned}
E_{\mathrm{CAP}, \mathrm{B}}^{\mathrm{BAT}}-G \cdot b^{\mathrm{BAT}} & \leq 0, b=1 \ldots B \\
n_{i}^{\mathrm{MOD}}-G \cdot b^{\mathrm{PV}} & \leq 0, i=1 \ldots N
\end{aligned}
$$

\section{Performance indicators}

To assess the performance of the design and operation resulting from the optimization, a set of performance indicators is defined in Table 4. First, the design is evaluated through the PV hosted capacity, which represents the relative installed PV capacity, the energy curtailed ratio, and the battery autonomy. The levelized cost of energy takes into account the entire lifetime costs, which include the potential component replacements. Typically, the battery's lifetime is much shorter than the system's, which is estimated according to the degradation model proposed by Xu et al. (2018). This model requires as an input the state of charge time series (ratio $E_{t}^{\mathrm{BAT}} / E_{\mathrm{CAP}}^{\mathrm{BAT}}$ ), replicated $L$ times to emulate the entire lifetime operation. The battery is considered at its end of life when the capacity loss reaches $20 \%$ of the initial capacity. The system operation is assumed to be identical from year to year. This assumption allows for replication of the operation variables to mimic the entire

Table 3 CAPEX parts

\begin{tabular}{ll}
\hline pv & $C X_{\mathrm{pv}}=\sum_{i=1}^{N} n_{i}^{\mathrm{MOD}} \cdot P_{\mathrm{nOOM}, i}^{\mathrm{MOD}} \cdot C_{i}^{\mathrm{MOD}}+b^{\mathrm{PV}} \cdot \mathrm{CF}^{\mathrm{PV}}$ \\
\hline battery & $C X_{\mathrm{bat}}=\sum_{b=1}^{B} E_{\mathrm{CAP}, \mathrm{B}}^{\mathrm{BAT}} \cdot C^{\mathrm{BAT}, \mathrm{B}}+b^{\mathrm{BAT}} \cdot C_{F}^{\mathrm{BAT}}$ \\
\hline
\end{tabular}


Table 4 Performance indicators

\begin{tabular}{|c|c|c|}
\hline Indicator & Description & Formula \\
\hline PV hosted capacity & $\begin{array}{l}\text { Ratio between the installed PV } \\
\text { capacity and the potential PV } \\
\text { capacity of the roof }\end{array}$ & $P V_{\text {host }}=\frac{\sum_{i=1}^{N} n_{i}^{\text {MOD }} \cdot P_{\text {nom }}, i}{P V_{\text {potential }}}$ \\
\hline energy curtailed ratio & $\begin{array}{l}\text { Fraction of the total PV production } \\
\text { curtailed }\end{array}$ & $P V_{\text {curt }}=\frac{\sum_{t} P_{t}^{\text {CUR }}}{\sum_{t} P V_{t}}$ \\
\hline battery autonomy ratio & $\begin{array}{l}\text { Ratio between the installed battery } \\
\text { capacity and the mean daily energy } \\
\text { consumption }\end{array}$ & BAT $_{\text {aut }}=\frac{\sum_{b=1}^{B} E_{\mathrm{CA}, b}^{\mathrm{BAT}}}{\text { mean daily energy }}$ \\
\hline net present value & $\begin{array}{l}\text { The total net present value of the } \\
\text { system (including battery } \\
\text { replacement) }\end{array}$ & $\mathrm{NPV}=\frac{\sum_{t=1}^{L} \mathrm{CF}_{t}}{(1+r)^{t}}$ \\
\hline levelized cost of energy & $\begin{array}{l}\text { The NPV divided by the total } \\
\text { consumed energy }\end{array}$ & $L C O E=\frac{N P V}{L \cdot \sum_{t} P_{t}^{P^{O A D D} \cdot T S_{t}}}$ \\
\hline self-consumption & $\begin{array}{l}\text { Share of the PV production directly } \\
\text { consumed by the system }\end{array}$ & $\mathrm{SC}=\frac{\sum_{t \in T} \min \left(P_{t}^{\mathrm{LOAD}}+P_{t}^{\mathrm{CHA}}, P_{t}^{\mathrm{PV} V}\right)}{\sum_{t \in T}^{P_{t}^{\mathrm{PV}}}}$ \\
\hline grid usage ratio & $\begin{array}{l}\text { Ratio between the maximum } \\
\text { import, export power, and the } \\
\text { maximum load power }\end{array}$ & $G U_{I M P, E X P}=\frac{\max P_{t}^{I M P, E X P}}{\max P_{t}^{L D A D}}$ \\
\hline
\end{tabular}

lifetime but does not take into account the impact of the PV module degradation or the battery capacity fading. Finally, a cash-flow table $\mathrm{CF}_{t}$ is constructed to compute the net present value (as defined in Table 4).

\section{Case study}

The data sources for the technology costs were extracted from various prospective market studies (IRENA 2016; 2017) and current Swiss market data (SFOE). "Investment costs" section depicts the methodology we used to extract the relevant information. The reference year was chosen to be 2030 , as it is the time horizon of the cited data sources. The model was applied to a case study consisting of a single-family building with four available roof planes, each with its orientation as described in "House" section. Five different tariff structures are investigated: three of them are volumetric-based tariffs, one is capacitybased, and the last one is a block rate tariff. The design of these tariffs is explained in "Tariffs" section. Finally, all parameters are summarized in Table 5 .

\section{Investment costs}

The specific cost evolution, as well as the efficiency forecast, of an LMO battery is given in the IRENA report (IRENA 2017). The given values can be fitted using a rational fit as in Eq. 19.

$$
\begin{aligned}
C^{\mathrm{BAT}} & =\frac{p_{1}}{\text { year }+q_{1}} \\
C^{\mathrm{MOD}} & =0.83 \frac{p_{2}}{\text { year }+q_{2}}
\end{aligned}
$$

where $p_{1}=4468.8$ and $q_{1}=-2005.5$, which gives a specific battery cost for 2030 of $C^{\mathrm{BAT}}=$ 182.4 CHF/kWh. Since no information is available about the fixed costs, they are set to 0 . As regards the PV, based on a large number of quotes in Switzerland, the Swiss federal office for energy (SFOE) (SFOE) gives for the year 2018 the following installation costs: $C^{\mathrm{MOD}}=1.19 \mathrm{CHF} / \mathrm{W}$ and $C_{F}^{\mathrm{pV}}=2749 \mathrm{CHF}$. Then by fitting the yearly cost decrease given 
Table 5 Parameters

\begin{tabular}{|c|c|c|c|c|c|}
\hline & Parameter & Set & Unit & Value & Description \\
\hline \multirow[t]{3}{*}{ TIME } & $T$ & $\mathbb{N}$ & - & 35040 & number of time steps \\
\hline & M & $\mathbb{N}$ & - & 12 & number of months \\
\hline & TS & $\mathbb{R}_{+}^{T}$ & s & $900^{1}$ & time steps \\
\hline \multirow[t]{11}{*}{ PV } & N & $\mathbb{N}$ & - & 4 & number of PV configurations \\
\hline & J & $\mathbb{N}$ & - & 4 & number of roof planes \\
\hline & $\mathrm{CF}^{\mathrm{PV}}$ & $\mathbb{R}_{+}$ & $\mathrm{CHF}$ & 2749 & PV fixed cost \\
\hline & $C^{M O D}$ & $\mathbb{R}_{+}^{N}$ & CHF/W & $0.610^{1}$ & PV configurations, specific costs \\
\hline & $P_{\text {nom }}^{\text {Mod }}$ & $\mathbb{R}_{+}^{N}$ & W & $315^{1}$ & PV unit nominal power \\
\hline & $P^{M O D}$ & $\mathbb{R}_{+}^{T \times N}$ & W & 2 & PV configuration unit generation \\
\hline & $A^{\mathrm{MOD}}$ & $\mathbb{R}_{+}^{N}$ & $m^{2}$ & $1.631^{1}$ & PV configuration areas \\
\hline & $A^{\text {ROOF }}$ & $\mathbb{R}_{+}^{\lrcorner}$ & $\mathrm{m}^{2}$ & $23^{1}$ & roof planes areas \\
\hline & $\gamma^{P V}$ & $\mathbb{R}$ & - & $0.5 \%$ & annual maintenance specific cost \\
\hline & $\beta_{i}$ & {$[0-90]^{N}$} & deg & 3 & \\
\hline & $\omega_{i}$ & {$[0-360]^{N}$} & deg & 3 & PV configuration azimuth \\
\hline \multirow[t]{12}{*}{ BATTERY } & B & $\mathbb{N}$ & - & 1 & number of batteries \\
\hline & $\mathrm{sOC}_{0}$ & {$[0,1]^{B}$} & - & 0.7 & initial state of charge \\
\hline & $\mathrm{SOC}_{\min }$ & {$[0,1]^{B}$} & - & 0 & minimum state of charge \\
\hline & $\mathrm{SOC}_{\max }$ & {$[0,1]^{B}$} & - & 0.7 & maximum state of charge \\
\hline & $\alpha$ & $\mathbb{R}_{+}^{B}$ & $s^{-1}$ & $4.63 \cdot 10^{-7}$ & battery self-discharge rate \\
\hline & $\eta^{\mathrm{CHA}}$ & {$[0,1]^{B}$} & - & 0.98 & battery charging efficiency \\
\hline & $\eta^{D / S}$ & {$[0,1]^{B}$} & - & 0.98 & battery discharging efficiency \\
\hline & $\gamma^{\mathrm{CHA}}$ & $\mathbb{R}_{+}^{B}$ & $1 / \mathrm{s}$ & $1 / 3600$ & battery charge $C$ rate \\
\hline & $\gamma^{D I S}$ & $\mathbb{R}_{+}^{B}$ & $1 / \mathrm{s}$ & $1 / 3600$ & battery discharge $\mathrm{C}$ rate \\
\hline & $C^{B A T}$ & $\mathbb{R}_{+}^{B}$ & $\mathrm{CHF} / \mathrm{J}$ & $5.07 \cdot 10^{-54}$ & battery specific cost \\
\hline & $C_{F}^{B A T}$ & $\mathbb{R}_{+}^{B}$ & $\mathrm{CHF}$ & 0 & battery fixed cost \\
\hline & $C_{O}^{B A T}$ & $\mathbb{R}_{+}^{B}$ & $\mathrm{CHF} / \mathrm{J}$ & 0 & operational cost of storage \\
\hline \multirow[t]{3}{*}{ SYSTEM } & L & $\mathbb{N}$ & years & 25 & system lifetime \\
\hline & $L^{B A T}$ & $\mathbb{R}_{+}$ & years & 9 & expected battery lifetime \\
\hline & r & $\mathbb{R}$ & - & $1.5 \%$ & discount rate \\
\hline
\end{tabular}

unique value for al

${ }^{2}$ PV profiles are simulated using the PVLIB toolbox (Stein et al. 2016)

${ }^{3} \mathrm{PV}$ configuration tilt and azimuth are given in Fig. 4

${ }^{4}$ equivalent to $182.4 \mathrm{CHF} / \mathrm{kWh}$

in the IRENA report (IRENA 2016) using a rational fit again, the specific cost can be expressed as in Eq. 20, where $q_{2}=-2005.4, p_{2}=18141.0$ and 0.83 is the ratio between the SFOE specific cost and the one from IRENA for 2018. In this prospective research, all results presented in "1" section are obtained considering the investment costs for the year 2030.

\section{House}

The considered building, located in the Neuchâtel area, has four roof planes of $23 \mathrm{~m}^{2}$ each, oriented approximately toward the four cardinal directions, and tilted at $24 \mathrm{deg}$. A photograph of the house and the exact tilt and orientation of the roof planes are shown in Fig. 4. The garage roof next to the house is not considered since its potential energy yield 


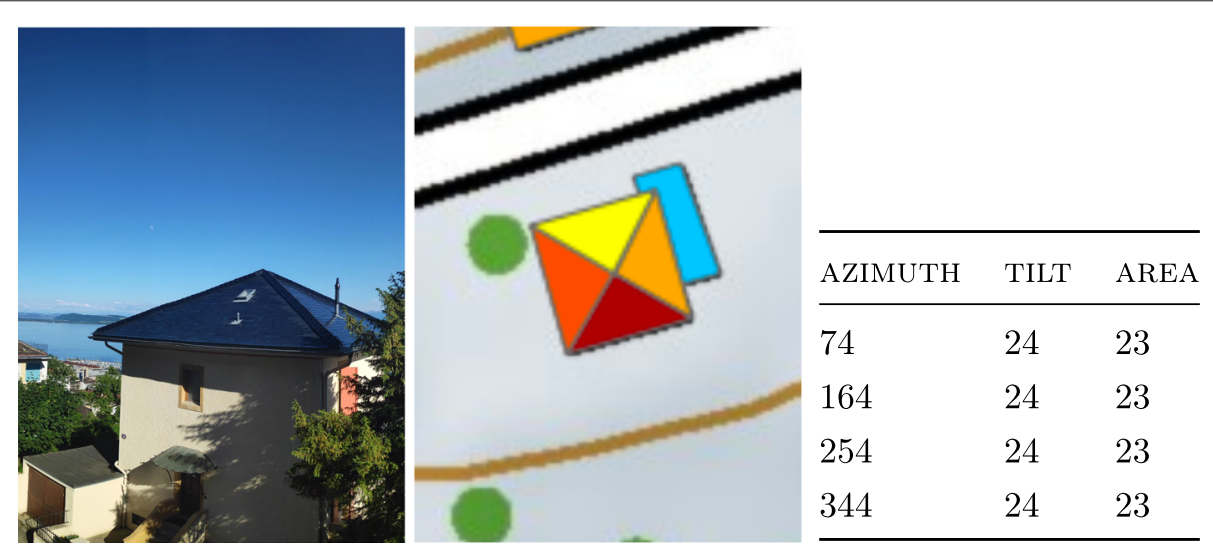

Fig. 4 Reference house

is too low due to the shadow from the house. Thus, the maximum PV capacity for this building is about $12 \mathrm{~kW}$. The electricity consumption profile comes from a household of two people with an annual consumption of $5008 \mathrm{kWh}$ while the weather data comes from the meteoSwiss weather station of Mühleberg ${ }^{1}$. Weather data and the load measurement are contemporary.

\section{Tariffs}

We investigate the optimal design and operation of the system under five different tariff scenarios, inspired by the most up-to-date literature but never used in this context. The first, and reference, scenario is a real tariff applied by the utility Romande Energie SA. It is a common time-of-use tariff in Switzerland with a low rate during the nights of Monday to Friday and during the weekend (Romande 2019). The second scenario is a fictive solar tariff which incentives the households to consume more during midday in order to selfconsume solar energy. The third is a mirror of the intraday continuous price from the EPEX $^{2}$. The fourth is composed of a capacity-based tariff to cover the grid cost while constant volumetric tariffs are applied for the energy exchange. The last scenario consists of a block rate tariff. To reduce bias, the tariff of each scenario is adjusted so that the grid cost and the energy retail cost (or revenue) are identical to the reference case when using the optimal design and operation of the reference scenario. As no grid charge is defined for the spot market scenario, the EPEX market price is scaled so that the total cost of importing energy from the grid would stay the same when using the reference scenario system design. The same applies to the export price, which is the EPEX price scaled so that the export revenue would stay the same as for the reference scenario. Similarly, the block rate tariff does not contain any grid charge, and the values of the power threshold and of the tariff are scaled so that the total import cost and export revenue remain identical. The import/export tariff and grid charges are summarized for all scenarios in Table 6. For the block rate tariff, the value indicates the tariff (per kWh) between the power interval specified in brackets. The negative value for the export price indicates that the system earns less money per additional $\mathrm{kW}$ above $4 \mathrm{~kW}$ feed to the grid than for lower injection power, corresponding to a negative slope of the third segment of the block rate tariff

${ }^{1}$ data are available at https://gate.meteoswiss.ch/idaweb/

${ }^{2}$ https://www.epexspot.com/en/market-data/intradaycontinuous/intraday-table/-/CH 
Table 6 Scenarios and tariff structures

\begin{tabular}{lllll}
\hline Scenario & import (cts/kWh) & & export (cts/kWh) & grid charges \\
\hline \multirow{2}{*}{ reference } & Mon-Fri 22h-6h & 7.58 & & $7.58 \mathrm{cts} / \mathrm{kWh}$ \\
& Sat-Sun & 7.58 & 8.16 & $7.58 \mathrm{cts} / \mathrm{kWh}$ \\
& Mon-Fri 6h-22h & 11.96 & & $11.96 \mathrm{cts} / \mathrm{kWh}$ \\
solar tariff & $11 \mathrm{~h}-15 \mathrm{~h}$ & 5.48 & 6.43 & $5.48 \mathrm{cts} / \mathrm{kWh}$ \\
& $15 \mathrm{~h}-11 \mathrm{~h}$ & 8.64 & 10.14 & $8.64 \mathrm{cts} / \mathrm{kWh}$ \\
spot market & EPEX scaled by 3.247 & & EPEX scaled by 1.568 & - \\
capacity & 8.54 & & 8.16 & $1.87 \mathrm{CHF} / \mathrm{kW} / \mathrm{month}$ \\
& $16[0-2] \mathrm{kW}$ & & $15[0-2] \mathrm{kW}$ & \\
block rate tariff & $34[2-4] \mathrm{kW}$ & & $9[2-4] \mathrm{kW}$ & - \\
& $66.66[4-\infty] \mathrm{kW}$ & & $-4.67[4-\infty] \mathrm{kW}$ & \\
\hline
\end{tabular}

illustrated in Fig. 3. It does not mean that the system is paying for injecting power above $4 \mathrm{~kW}$. However, this is possible if the system is injecting at a power above $14.3 \mathrm{~kW}$.

\section{Results and discussion}

The design and control optimization is evaluated over a full year with a temporal resolution of $15 \mathrm{~min}$ for each tariff scenario described in the previous section using GUROBI (Gurobi Optimization 2019) to solve the MILP problem. Optimization runtime ranges from 2 to $5 \mathrm{~min}$ with the volumetric tariffs whereas it takes close to $30 \mathrm{~min}$ to solve the capacity and block rate scenarios on an Intel(R) Xeon(R) CPU E5-2630 v3 @ 2.40GHz processor with 8 Cores and 32GB of RAM. Figure 5 illustrates the operation under the block rate tariff scenario. Both PV curtailment and the battery are widely used to minimize the total annualized cost (Eq. 11 from "Methodology" section). The amplitude of the grid exchange is strongly limited, and the import and export powers are likely to match with the power threshold of the block rate tariff (i.e. 2000 or $4000 \mathrm{~W}$ ).

All performance indicators defined in Table 4 have been evaluated for each tariff scenario. Figure 6 shows the indicators related to the system design, Fig. 7 shows those related to the economic performance and Fig. 8 shows those related to the grid usage. Due to the low cost of PV and the limited roof area, the maximum PV hosted capacity is reached in each case. The three first scenarios are based only on an energy tariff that does

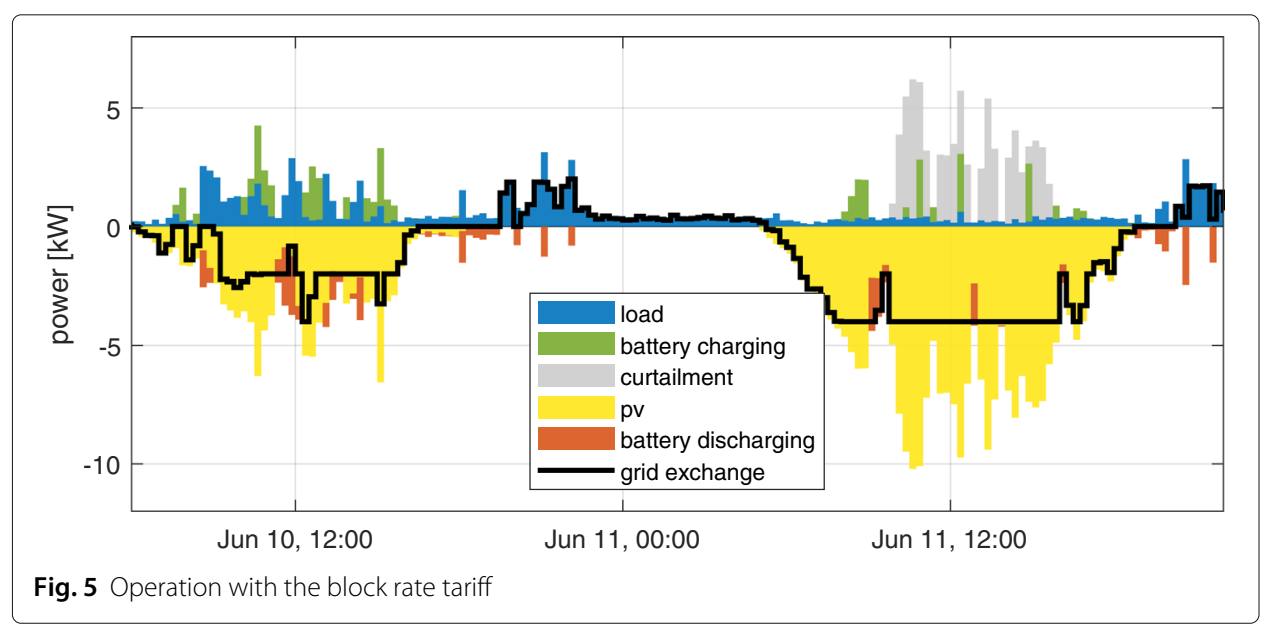




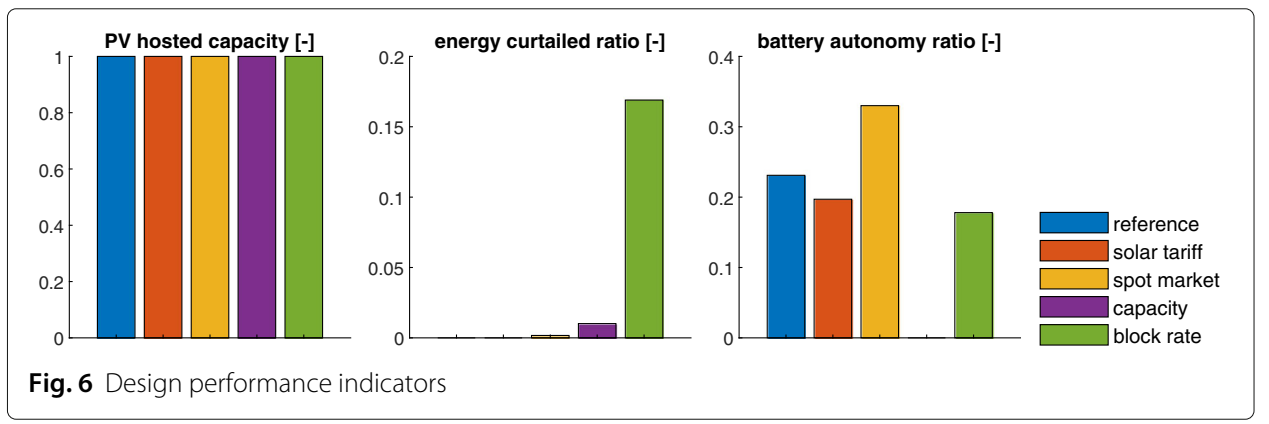

not give any incentive to curtail the PV generation. However, a few exceptions occur with the spot market tariff when going negative and lead to curtailment of the PV generation. However, both the capacity and block rate tariff scenarios give a financial incentive to curtail the PV generation. With the capacity tariff, only $1 \%$ of the generation is curtailed to cut the exported power peaks and minimize the maximum monthly peaks. With the block rate tariff, due to the strong decrease of the revenue above $4 \mathrm{~kW}$, the energy generated above this power is either stored or curtailed, leading to an energy curtailed ratio of $17 \%$. The capacity-based tariff does not encourage investment in the battery system, and conversely, the spot market scenario with higher tariff variations makes the use of a battery more profitable.

As regards the economic performance indicators, all the advanced tariff scenarios show a higher revenue and a lower system LCOE compared to reference. Although the block rate tariff has been defined such that the import and export cost remain identical, the high export tariff at low power allows for reaching a very low LCOE. The a posteriori computed battery lifetimes are close to the expected lifetime (9 years) used in the CAPEX formulation of Eq. 13. Only the spot market scenario gives a higher incentive to use the battery and shows a decrease in the battery lifetime of $26 \%$. This would negatively impact the financial performance of the system. For such a case where battery usage is very intensive, the degradation costs should be directly integrated into the objective function. However, due to the strong non-linearity of those costs, this will be investigated in a future work.

The variation of the spot market tariff along the day pushes to increase selfconsumption. However, its volatility can sometimes encourage to discharge the battery when PV generation is already at its maximum, leading to very high export grid usage. Only the block rate tariff allows decreasing both the import and export grid usage significantly using, as shown in Fig. 5, a combination of PV curtailment and storage to flatten the grid exchanges.

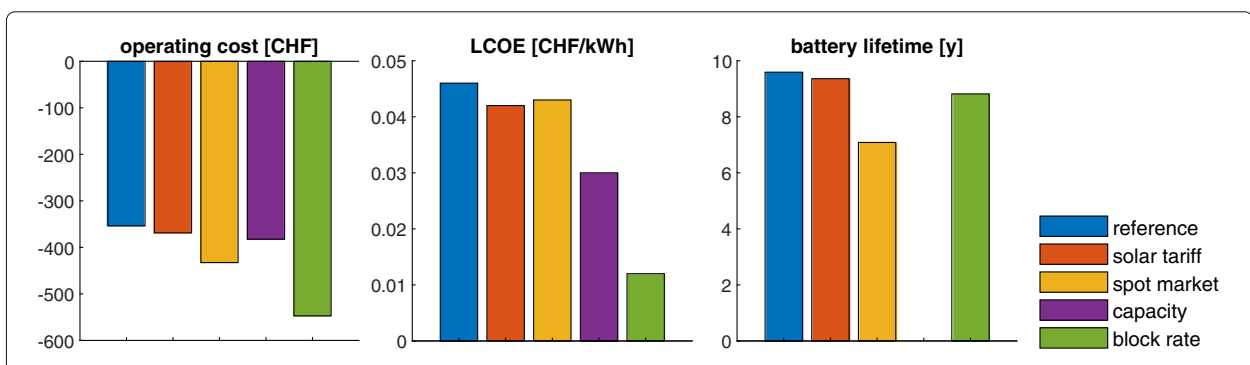

Fig. 7 Economic performance indicators 


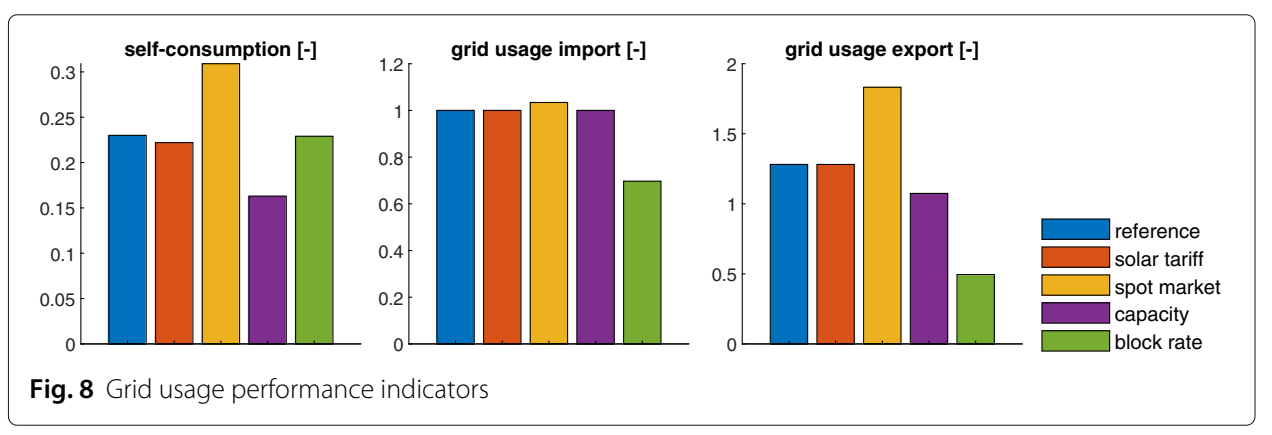

\section{Conclusions}

In this work, we provided an integrated optimization method able to find the optimal design and operation of a grid-connected PV-battery system. We also provided an integration in a mixed integer linear formulation of advanced dynamic tariff structures such as capacity-based and block rate tariff, which has never been done in combination with the sizing of both the PV and battery capacity. The impact of five different tariff structures on the design and operation of the system was assessed. The results highlighted the profitability of investing in PV in all scenarios while the investment in a battery is emphasized by dynamic prices that create a revenue opportunity. Simple capacity-based tariffs do not provide sufficient incentives to invest in a battery system if the capacity cost is dominated by the PV injection power, which can be easily curtailed. The addition of $12 \mathrm{~kW}$ of PV increases the grid usage ratio (defined in Table 4) by about $30 \%$ under a standard double volumetric tariff. We showed that the addition of a capacity-based tariff helps to moderate grid usage, while a real-time pricing scheme from the EPEX intraday spot market significantly increases usage of the grid. The only tariff structure that showed a positive impact on grid usage while showing good economic opportunities is the block rate tariff. By nature, this tariff penalizes overuse of the grid. A combination of the spot market tariff with a block rate tariff is worth investigation, although it brings additional complexity. While volumetric tariffs are easy to understand and design for a distribution system operator, capacity tariffs already decrease accessibility for non-expert consumers. Regarding the block rate tariff, although our results showed promising opportunities for demandside management and network management, there is a lack of theory on how to design such tariff properly.

Future work will investigate the effectiveness of such tariffs at the grid level while evaluating potential mandatory equipment regulation (such as a minimum required battery capacity per kW of installed PV) and their technical and economic effects. As this work focused on a single house, the effect of the proposed tariff on the network cost recovery issue was not properly assessed. Future research will investigate how the network operation costs can be recovered by adding advanced tariffs given the reaction of individual systems to the price signal. Finally, the battery degradation will be integrated into the formulation of the mixed integer linear program allowing us to explore the trade-off between revenue generation and battery degradation costs. 


\section{Funding}

This research is part of the activities of the Swiss Centre for Competence in Energy Research on the Future Swiss Electrical Infrastructure (SCCER-FURIES), which is financially supported by the Swiss Innovation Agency (Innosuisse - SCCER program). Publication of this supplement was funded by Austrian Federal Ministry for Transport, Innovation and Technology.

\section{Availability of data and materials}

All data generated and analysed during the current study are available from the corresponding author on reasonable request.

\section{About this supplement}

About this Supplement This article has been published as part of Energy Informatics Volume 2 Supplement 1, 2019: Proceedings of the 8th DACH+ Conference on Energy Informatics. The full contents of the supplement are available online at https://energyinformatics.springeropen.com/articles/supplements/volume-2-supplement-1

\section{Competing interests}

The authors declare that they have no competing interests.

\section{Published: 23 September 2019}

\section{References}

Ansari B, Shi D, Sharma R, Simoes MG (2016) Economic analysis, optimal sizing and management of energy storage for PV grid integration. In: Proceedings of the IEEE Power Engineering Society Transmission and Distribution Conference. IEEE, Dallas, TX, USA Vol. 2016-July. pp 1-5. https://doi.org/10.1109/TDC.2016.7520090. http://ieeexplore.ieee.org/ document/7520090/

Ayompe LM, Duffy A (2013) Feed-in tariff design for domestic scale grid-connected PV systems using high resolution household electricity demand data. Energy Policy 61:619-627. https://doi.org/10.1016/j.enpol.2013.06.102

Azarova V, Engel D, Ferner C, Kollmann A, Reichl J (2018) Exploring the impact of network tariffs on household electricity expenditures using load profiles and socio-economic characteristics. Nature Energy 3(4):317-325. https://doi.org/10. 1038/s41560-018-0105-4

Beck T, Kondziella H, Huard G, Bruckner T (2016) Assessing the influence of the temporal resolution of electrical load and PV generation profiles on self-consumption and sizing of PV-battery systems. Appl Energy 173:331-342. https://doi. org/10.1016/j.apenergy.2016.04.050

Bonbright JC, Danielsen AL, Kamerschen DR (1961) Principles of Public Utility Rates. Columbia University, Press New York

Babacan O, Ratnam EL, Disfani VR, Kleissl J (2017) Distributed energy storage system scheduling considering tariff structure, energy arbitrage and solar PV penetration. Appl Energy 205:1384-1393. https://doi.org/10.1016/J. APENERGY.2017.08.025

Borenstein S (2017) Private Net Benefits of Residential Solar PV: The Role of Electricity Tariffs, Tax Incentives, and Rebates. J Assoc Environ Res Econ 4(S1):85-122. https://doi.org/10.1086/691978

Bucher C, Betcke J, Andersson G (2013) Effects of variation of temporal resolution on domestic power and solar irradiance measurements. 2013 IEEE Grenoble Confer PowerTech, POWERTECH 2013 March 2010:1-6. https://doi.org/10.1109/ PTC.2013.6652217

Darghouth NR, Wiser RH, Barbose G (2016) Customer economics of residential photovoltaic systems: Sensitivities to changes in wholesale market design and rate structures. Renew Sust Energ Rev 54:1459-1469. https://doi.org/10. 1016/J.RSER.2015.10.111

Deetjen TA, Vitter JS, Reimers AS, Webber ME (2018) Optimal dispatch and equipment sizing of a residential central utility plant for improving rooftop solar integration. Energy 147:1044-1059. https://doi.org/10.1016/J.ENERGY.2018.01.110

Devine MT, Farrell N, Lee WT (2017) Optimising feed-in tariff design through efficient risk allocation. Sust Energy, Grids Netw 9:59-74. https://doi.org/10.1016/.segan.2016.12.003

Dutta G, Mitra K (2017) A literature review on dynamic pricing of electricity. J Oper Res Soc 68(10):1131-1145. https://doi. org/10.1057/s41274-016-0149-4

Govaerts N, Bruninx K, Delarue E (2018) Impact of Distribution Tariff Design on the Profitability of Aggregators of Distributed Energy Storage Systems. In: 15th International Conference on the European Energy Market (EEM). IEEE, Łódź, Poland. pp 1-5. https://doi.org/10.1109/EEM.2018.8469793.https://ieeexplore.ieee.org/document/8469793/

Gurobi Optimization L (2019) Gurobi Optimizer 8.1, Reference Manual. http://www.gurobi.com. Accessed 14 Aug 2019

Heussen K, Koch S, Ulbig A, Andersson G (2010) Energy storage in power system operation: The power nodes modeling framework. PES Innov Smart Grid Technol Confer Europe, IEEE:1-8. https://doi.org/10.1 109/ISGTEUROPE.2010.5638865

Hinz F, Schmidt M, Möst D (2018) Regional distribution effects of different electricity network tariff designs with a distributed generation structure: The case of Germany. Energy Policy 113(November 2017):97-111. https://doi.org/ 10.1016/j.enpol.2017.10.055

Huber J, Richter B, Weinhardt C (2018) Are consumption tariffs still up-to-date? An operationalized assessment of grid fees. In: 15th International Conference on the European Energy Market, EEM. IEEE, Łódź, Poland Vol. 2018-June. pp 1-5. https://doi.org/10.1109/EEM.2018.8469847.https://ieeexplore.ieee.org/document/8469847/

IRENA (2017) Electricity Storage and Renewables: Costs and Markets to 2030. https://www.irena.org/publications/2017/ Oct/Electricity-storage-and-renewables-costs-and-markets. Accessed 2019-06-12

IRENA (2016) The power to change: solar and wind cost reduction potential to 2025. Tech Rep. https://www.irena.org/ publications/2016/Jun/The-Power-to-Change-Solar-and-Wind-Cost-Reduction-Potential-to-2025. Accessed 2019-06-12

Kubli M (2018) Squaring the sunny circle? On balancing distributive justice of power grid costs and incentives for solar prosumers. Energy Policy 114:173-188. https://doi.org/10.1016/J.ENPOL.2017.11.054 
Lauinger D, Caliandro P, Van herle J, Kuhn D (2016) A linear programming approach to the optimization of residential energy systems. J Energy Storage 7:24-37. https://doi.org/10.1016/j.est.2016.04.009

Milis K, Peremans H, Van Passel S (2018) Steering the adoption of battery storage through electricity tariff design. Renew Sust Energ Rev 98(September):125-139. https://doi.org/10.1016/j.rser.2018.09.005

Mulder G, Six D, Claessens B, Broes T, Omar N, Mierlo JV (2013) The dimensioning of PV-battery systems depending on the incentive and selling price conditions. Appl Energy 111:1126-1135. https://doi.org/10.1016/J.APENERGY.2013.03.059

O'Shaughnessy E, Cutler D, Ardani K, Margolis R (2018) Solar plus: Optimization of distributed solar PV through battery storage and dispatchable load in residential buildings. Appl Energy 213:11-21. https://doi.org/10.1016/J.APENERGY. 2017.12.118

Pena-Bello A, Burer M, Patel MK, Parra D (2017) Optimizing PV and grid charging in combined applications to improve the profitability of residential batteries. J Energy Storage 13:58-72. https://doi.org/10.1016/J.EST.2017.06.002

Ren Z, Grozev G, Higgins A (2016) Modelling impact of PV battery systems on energy consumption and bill savings of Australian houses under alternative tariff structures. Renew Energy 89:317-330. https://doi.org/10.1016/J.RENENE. 2015.12 .021

Romande E (2019) Prix. https://www.romande-energie.ch. Accessed 2019-04-12

Schibuola L, Scarpa M, Tambani C (2016) Parametric study on the financial performance of battery-supported photovoltaic systems connected to smart grids in current and future market scenarios. Sci Technol Built Environ 22(6):751-765. https://doi.org/10.1080/23744731.2016.1197717

Schittekatte T, Momber I, Meeus L (2018) Future-proof tariff design: Recovering sunk grid costs in a world where consumers are pushing back. Energy Econ 70:484-498. https://doi.org/10.1016/j.eneco.2018.01.028

Schreiber M, Wainstein ME, Hochloff P, Dargaville R (2015) Flexible electricity tariffs: Power and energy price signals designed for a smarter grid. Energy 93:2568-2581. https://doi.org/10.1016/J.ENERGY.2015.10.067

SFOE Calculateur solaire. https://www.suisseenergie.ch/page/fr-ch/calculateur-solaire. Accessed 2018-01-29

Simshauser P (2016) Distribution network prices and solar PV: Resolving rate instability and wealth transfers through demand tariffs. Energy Economics 54:108-122. https://doi.org/10.1016/J.ENECO.2015.11.011

Soares I, Alves MJ, Antunes CH (2019) Designing time-of-use tariffs in electricity retail markets using a bi-level model Estimating bounds when the lower level problem cannot be exactly solved. Omega. https://doi.org/10.1016/J. OMEGA.2019.01.005

Stein JS, Holmgren WF, Forbess J, Hansen CW (2016) PVLIB: Open source photovoltaic performance modeling functions for Matlab and Python. In: 2016 IEEE 43rd Photovoltaic Specialists Conference (PVSC). IEEE, Portland, OR, USA. pp 3425-3430

Stadler P, Ashouri A, Maréchal F (2016) Model-based optimization of distributed and renewable energy systems in buildings. Energy Build 120:103-113. https://doi.org/10.1016/j.enbuild.2016.03.051

Talent O, Du H (2018) Optimal sizing and energy scheduling of photovoltaic-battery systems under different tariff structures. Renew Energy 129:513-526. https://doi.org/10.1016/j.renene.2018.06.016

Theo WL, Lim JS, Ho WS, Hashim H, Lee CT (2017) Review of distributed generation (DG) system planning and optimisation techniques: Comparison of numerical and mathematical modelling methods. Renew Sust Energy Rev 67:531-573. https://doi.org/10.1016/j.rser.2016.09.063. arXiv:1011.1669v3

Wu X, Hu X, Yin X, Zhang C, Qian S (2017) Optimal battery sizing of smart home via convex programming. Energy 140:444-453. https://doi.org/10.1016/J.ENERGY.2017.08.097

Xu B, Oudalov A, Ulbig A, Andersson G, Kirschen DS (2018) Modeling of Lithium-lon Battery Degradation for Cell Life Assessment. IEEE Trans Smart Grid 9(2):1131-1140. https://doi.org/10.1109/TSG.2016.2578950

Young S, Bruce A, MacGill I (2016) Electricity network revenue under different Australian residential tariff designs and customer interventions. In: 2016 IEEE Power and Energy Society General Meeting (PESGM). IEEE, Boston, MA, USA. pp 1-5. https://doi.org/10.1109/PESGM.2016.7741536. http://ieeexplore.ieee.org/document/7741536/

Young, S, Bruce A, MacGill I (2019) Potential impacts of residential PV and battery storage on Australia's electricity networks under different tariffs. Energy Policy 128:616-627. https://doi.org/10.1016/J.ENPOL.2019.01.005

Zhang S, Tang Y (2019) Optimal schedule of grid-connected residential PV generation systems with battery storages under time-of-use and step tariffs. J Energy Storage 23:175-182. https://doi.org/10.1016/j.est.2019.01.030

\section{Publisher's Note}

Springer Nature remains neutral with regard to jurisdictional claims in published maps and institutional affiliations.

\section{Submit your manuscript to a SpringerOpen ${ }^{\circ}$ journal and benefit from:}

- Convenient online submission

- Rigorous peer review

- Immediate publication on acceptance

- Open access: articles freely available online

High visibility within the field

Retaining the copyright to your article 